\title{
Cardiac Death
}

National Cancer Institute

\section{Source}

National Cancer Institute. Cardiac Death. NCI Thesaurus. Code C54196.

The cessation of life due to heart abnormalities or disease. 